\title{
Effect of moisture and concrete composition on the Torrent permeability measurement
}

\author{
M. Romer ${ }^{1}$ \\ (1) Empa, Swiss Federal Laboratories for Materials Testing and Research, Laboratories for Concrete \& Construction \\ Chemistry, Überlandstrasse 129, CH-8600 Dübendorf, Switzerland
}

Received: 24 November 2004; accepted: 16 February 2005

\begin{abstract}
The change of the gas permeability of concrete with age and the effect of defined moisture conditions were investigated. Four different concrete mixtures were produced and stored in the laboratory at $35 \%, 70 \%$ and $90 \% \mathrm{RH}$. The air permeability of the covercrete was monitored with the Torrent method. Under controlled environmental conditions the Torrent method is sensitive to the concrete quality. However, when young concrete or moist concrete is tested adverse effects lead to unexpected results. The results of the non-destructive Torrent method are compared with data obtained with other methods and indicate significant influences of moisture under certain conditions. The effects of moisture on the results measured with the Torrent method and possibilities to improve the method for the application on real structures are discussed.

1359-5997 (C) 2005 RILEM. All rights reserved.

\section{RÉSUMÉ}

L'évolution de la perméabilité au gaz du béton en fonction de son âge et sous l'influence de différentes conditions d'humidité ont été étudiées en laboratoire. Des bétons de quatre compositions différentes ont été confectionnés et conditionnés à des humidités relatives de l'air de 35\%, 70\% et 90\% pour être ensuite testés périodiquement avec la méthode Torrent. Dans des conditions d'environnement constantes, la méthode Torrent est sensible et permet de différencier la qualité des bétons. Cependant pour les mesures effectuées sur des bétons jeunes ou pour les conditionnements à une humidité élevée, il apparaît des effets qui conduisent à des résullats inattendus. La comparaison des résultats obtenus avec la méthode non destructive qu'est la méthode Torrent avec ceux d'autres méthodes d'essai montre que l'humidité présente dans les éprouvettes influence directement les résultats obtenus avec la méthode Torrent. Ces effets sont discutés de même que les approches possibles pour améliorer cette méthode.
\end{abstract}

\section{INTRODUCTION}

Durability aspects are a major concern for concrete. Recent debates on sustainable development again draw the attention of authorities, of the research community and of standard organisations on long time performance of concrete.

The interaction of concrete with an aggressive environment is influenced by its porous microstructure and consequently by various transport mechanisms of gases and liquids. Although there are no general and accepted methods to characterize the relevant pore structure or to quantify the overall durability performance of concrete, the permeability of concrete seems to be a suitable measure to determine the resistance against the ingress of aggressive substances.
By designing a concrete structure exposed to chemical impacts the prime concern must be laid on the protective performance of the concrete surface - the 20 to $50 \mathrm{~mm}$ thick layer called "covercrete" [1].

Acceptance criteria for concrete quality are well established but are mostly based on the mix design or specific properties of separately moulded concrete specimens. Although high strength concrete tends to be more durable than lower strength concrete, other properties than the compressive strength need to be considered to characterize adequately the durability of a concrete structure. Even more important is the fact that in real structures especially the covercrete is detrimentally affected by the placement and curing operations during construction $[2,3]$. Though there is a need to formulate specific 
performance criteria for the protective quality of the covercrete as well as to establish suitable test methods.

Several test methods to characterize the penetrability of the covercrete have been developed over the years $[4,5]$. Due to its non destructive nature and the correlation with well established laboratory methods we decided to further investigate the applicability and meaningfulness of the Torrent air permeability test method $[6,7]$. Furthermore the method is prescribed by the Swiss standard for quality control of concrete on site [8]. In view of the debates about the preconditioning of concrete samples for permeability testing [9] the impacts of moisture on field methods for gas permeability are a major concern [10].

The objective of this paper is to present and discuss various effects of concrete composition and moisture conditions on the validity of Torrent permeability data based on laboratory experiments.

\section{EXPERIMENTAL}

The concept of this study is based on the monitoring of the covercrete permeability with the Torrent method over a period of up to one year while exposing concrete samples to defined climates. Four concrete compositions were produced to represent a range of water to cement $(\mathrm{w} / \mathrm{c})$ ratios from 0.35 to 0.62 (Table 1). Ordinary Portland cement was used and the paste volume was adjusted to 260 \pm 10 litres per cubic meter concrete. Aggregates with a standard grain size distribution up to $32 \mathrm{~mm}$ were used. Cubes were cast for the monitoring of the covercrete permeability ( $200 \mathrm{~mm}$ size) and for the determination of the compressive strength development (150 $\mathrm{mm}$ size).

The $200 \mathrm{~mm}$ cubes were coated on four sides leaving two opposite sides uncovered (simulating a wall section) for the interaction with the environment and for the in-situ permeability measurements. The coating was done 48 hours after the production of the concrete (keeping it above $90 \% \mathrm{RH}$ ) and from then on the samples were stored in controlled environments at $20^{\circ} \mathrm{C}$ and $35 \%, 70 \%$ or $90 \% \mathrm{RH}$ respectively. The permeability was always measured at four identical locations on the samples (results given as mean values).

\begin{tabular}{|c|c|c|c|c|c|}
\hline \multicolumn{6}{|c|}{$\begin{array}{l}\text { Table } 1 \text { - Concrete composition and properties } \\
\text { (ordering: cement content, w/c ratio) }\end{array}$} \\
\hline \multicolumn{2}{|c|}{ Concrete mixture } & M1 & M3 & M2 & M5 \\
\hline Cement' & $\mathrm{kg} / \mathrm{m}^{3}$ & 380 & 325 & 300 & 275 \\
\hline Aggregate & $\mathrm{kg} / \mathrm{m}^{3}$ & 1898 & 1909 & 1921 & 1963 \\
\hline Water & $\mathrm{kg} / \mathrm{m}^{3}$ & 133 & 130 & 145 & 171 \\
\hline $\mathrm{w} / \mathrm{c}$ ratio & & 0.35 & 0.40 & 0.48 & 0.62 \\
\hline$L P$ & $\%$ & 2.8 & 3.2 & 1.7 & 2.0 \\
\hline$f_{c 28}$ & $\mathrm{MPa}$ & 55.3 & 48.1 & 47.4 & 35.0 \\
\hline$f_{c} 365$ & $\mathrm{MPa}$ & 62.6 & 53.9 & 51.8 & 38.3 \\
\hline
\end{tabular}

1 CEM I 42.5
The distinctive features of the Torrent permeability method are a two-chamber cell and a regulator that balances the vacuum pressure of the outer (guard-ring) chamber to the inner (measuring) chamber [7]. By applying the twochamber vacuum cell on a concrete surface it is therefore possible to generate a unidirectional gas flow into the inner chamber. Based on a measured pressure growth and an assumption on the relevant porosity of the concrete tested its gas permeability $\mathrm{kT}$ is calculated:

$$
k T=\left(\frac{V_{C}}{A}\right)^{2} \cdot \frac{\mu}{2 \varepsilon P_{a}}\left[\frac{\ln \left(\frac{P_{a}+\Delta P}{P_{a}-\Delta P}\right)}{\sqrt{t}-\sqrt{t_{0}}}\right]^{2} \quad\left[\mathrm{~m}^{2}\right]
$$

$\mathrm{V}_{\mathrm{C}}$ : volume of measuring (inner) cell $\left(2.2 \cdot 10^{-6} \mathrm{~m}^{3}\right)$

A: cross section of measuring cell $\left(19.6 \cdot 10^{-4} \mathrm{~m}^{2}\right)$

$\mu$ : viscosity of air at $20^{\circ} \mathrm{C}\left(2.0 \cdot 10^{-5} \mathrm{Ns} / \mathrm{m}^{2}\right)$

$\varepsilon: \quad$ porosity of concrete $(0.15)$

$\mathrm{P}_{\mathrm{a}}: \quad$ atmospheric pressure $\left(\approx 1000 \mathrm{~N} / \mathrm{m}^{2}\right)$

$\Delta \mathrm{P}: \quad$ pressure increase, measuring cell $\left(<20 \mathrm{~N} / \mathrm{m}^{2}\right)$

$\mathrm{t}_{0}: \quad$ setting of stopcock, start of measurement $(60 \mathrm{~s})$

$\mathrm{t}$ : duration of measurement $(<720 \mathrm{~s})$

The measurements of the electrical resistance with the Wenner method as recommended by Torrent and Frenzer [6] turned out to be restricted because a profound wetting of the sample surface was not possible. This method was therefore excluded from the study. The moisture content was determined with the Tramex Concrete Encounter Moisture Meter [11] before each kT measurement. This hand-held electronic instrument utilizes non-destructive impedance measurements for the moisture determination of the concrete cover (slightly more than $10 \mathrm{~mm}$ ). The upper limit of the method is 6 weight-percent.

At the age of one month and one year respectively half the samples were selected and used to determine the reference properties. As such the Cembureau method [12] was used to measure the oxygen-permeability $\mathrm{kO}$ of cores (150 $\mathrm{mm}$ in diameter and $50 \mathrm{~mm}$ high) containing the original cube surface as well as the test location of the Torrent method. Although the two permeability methods affect different sample volumes and use different preconditionings the test results will be compared directly. The core samples were dried at $50^{\circ} \mathrm{C}$ for 6 days and stored for one day in the desiccator.

Water conductivity and porosity were determined according to a Swiss national standard [8] on core samples $(50 \mathrm{~mm}$ in diameter and $50 \mathrm{~mm}$ long, the top $20 \mathrm{~mm}$ including the concrete surface were removed). Porosity was measured as the difference in mass of the water saturated sample to the dried $\left(100^{\circ} \mathrm{C}\right)$ sample. The capillary porosity was similarly obtained as the difference in mass of the water saturated sample to the sample dried at $50^{\circ} \mathrm{C}$ to constant weight. The water conductivity $\mathrm{q}_{\mathrm{w}}$ was determined based on the rate of water uptake of the $50^{\circ} \mathrm{C}$ dried sample immersed $3 \mathrm{~mm}$ deep in water. Because the porosity results showed only minor effects of the storing conditions the data in Table 2 represent the average values over all three storage conditions. 


\begin{tabular}{|l|l|l|c|c|c|c|}
\hline \multicolumn{6}{|c|}{ Table 2 - Porosity and water conductivity } \\
\hline \multirow{2}{|c|}{$\begin{array}{c}\text { Concrete mixture } \\
\text { Property }\end{array}$} & M1 & M3 & M2 & M5 \\
\hline \multirow{3}{*}{$\begin{array}{l}28 \\
\text { days }\end{array}$} & porosity & Vol.\% & 9.5 & 9.8 & 10.4 & 12.4 \\
\cline { 2 - 7 } & cap. por. & Vol.\% & 5.0 & 7.1 & 6.2 & 9.0 \\
\cline { 2 - 7 } & $\mathrm{q}_{\mathrm{w}}$ & $\mathrm{g} / \mathrm{m}^{2} \mathrm{~h}$ & 5.0 & 5.7 & 6.7 & 15.0 \\
\hline \multirow{3}{*}{$\begin{array}{l}365 \\
\text { days }\end{array}$} & porosity & $\mathrm{Vol. \%}$ & 9.4 & 9.4 & 10.4 & 12.6 \\
\cline { 2 - 7 } & cap. por. & $\mathrm{Vol. \%}$ & 4.4 & 5.1 & 5.7 & 8.7 \\
\cline { 2 - 7 } & $\mathrm{q}_{\mathrm{w}}$ & $\mathrm{g} / \mathrm{m}^{2} \mathrm{~h}$ & 4.0 & 3.7 & 5.3 & 12.7 \\
\hline
\end{tabular}

${ }^{1}$ cap. por. $=$ capillary porosity, $\mathrm{q}_{\mathrm{w}}=$ water conductivity

The $150 \mathrm{~mm}$ cubes were stored at the same conditions as the $200 \mathrm{~mm}$ cubes and tested for compressive strength at the age of 7 days, 28 days and one year (two samples each) to investigate the bulk effect of different storing conditions (curing).

\section{RESULTS}

\subsection{Effects of storage condition}

The moisture content of samples stored at $90 \% \mathrm{RH}$ could not be determined with the Tramex method because they contained significantly more than $6 \%$ moisture. The instrument readings of concrete samples stored at $70 \%$ and $35 \% \mathrm{RH}$ show a steady decrease in the moisture content over time (approximately proportional to the logarithm of time, Fig. 1). After storage at intermediate (70\%) humidity over one year the moisture values range form 4 to $5 \%$. For the same set of concrete stored at $35 \% \mathrm{RH}$ the moisture contents range from 4 to $5 \%$ at the age of 7 days and decrease towards 2 to $3 \%$ at the age of one year. In both regimes there is a tendency of concretes with low w/c ratios to show higher moisture contents than those with high w/c ratios. It has to be kept in mind that the moisture content (Tramex value) is not representative for the whole cube samples but for a rather thin surface layer.

The evolution of the covercrete permeability was monitored from the age of 7 days until 1 year. The results indicate different characteristics depending on the RH during storage and on the concrete quality (Fig. 2). Under dry $(35 \% \mathrm{RH})$ conditions the values of covercrete permeability kT tend do decrease slightly until the age of 1 month. From then on the permeability increases more or less steadily. The samples of the concrete mixtures with low water to cement ratios show the lowest, the samples with high $w / c$ ratio the highest permeability values. Under intermediate $(70 \%) \mathrm{RH}$ the impact of the duration of storage is reduced compared to dry conditions. At the storage condition of $90 \% \mathrm{RH}$ all concrete mixtures except M1 (lowest $w / c$ ) show almost no permeability increase over time.

Young samples (less than one month) show the lowest permeability values at $35 \% \mathrm{RH}$ followed by intermediate and humid conditions. Towards the age of one year the values for the high w/c concrete samples (M5) decrease with increased humidity of the storage conditions whereas the permeability

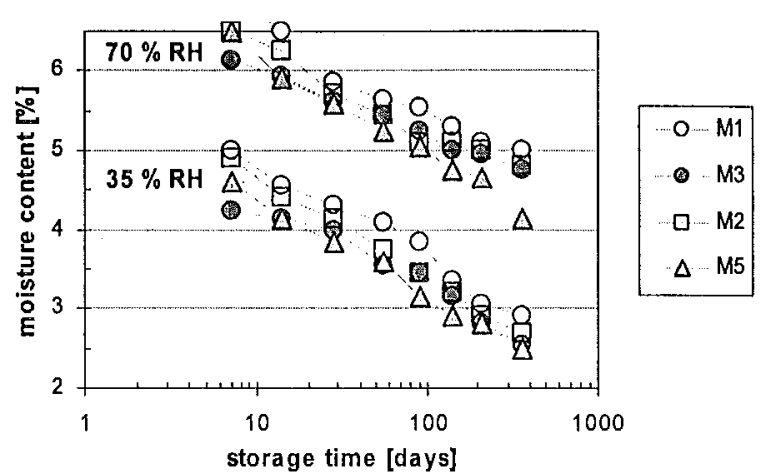

Fig. 1 - Near surface moisture content (Tramex method) of concrete samples stored at $35 \%$ and $70 \% \mathrm{RH}$ conditions (mean values of four measurements each on independent samples).
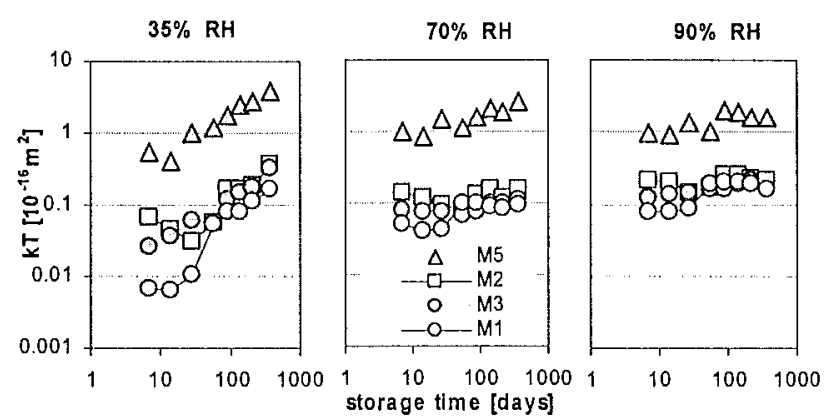

Fig, 2 - Evolution of covercrete permeability kT over periods of 1 year under defined humidity conditions and $20^{\circ} \mathrm{C}$ (geometrical mean values of four independent deterninations).

values of denser concrete samples (M1-3) tend to decrease form $35 \%$ towards $70 \%$ and then rise again towards $90 \% \mathrm{RH}$ (see Fig. 6a).

\subsection{Moisture effects on kT measurement}

The evolutions of the gas pressure in the measuring chamber for representative measurements at the age of 28 days and 1 year respectively are shown in Fig. 3. Compared to the original principle of the method the commercial equipment uses a simplified calculation algorithm [6] which is not taking into account the actual pressure evolution of the air-filling stage. For the calculation of the air permeability $\mathrm{kT}$ only the final pressure in the inner chamber, the time used to reach this pressure and the atmospheric pressure are used (1). As can be seen in Fig. 3 the shape of the pressure evolution curves of individual measurements is quite variable.

Samples stored in dry air show an almost linear pressure evolution in relation to the square root of measuring time. Concrete samples stored at $90 \%$ RH show a fast pressure increase at the beginning of the measurement (higher than all samples stored at intermediate or low RH) followed by a markedly reduced pressure increase. This change in pressure increase behaviour takes place at measured pressures in the inner cell of 6 to 14 mbar. The evolution of the chamber pressure of samples stored at high (90\%) RH is almost identical for all different concrete qualities used in 

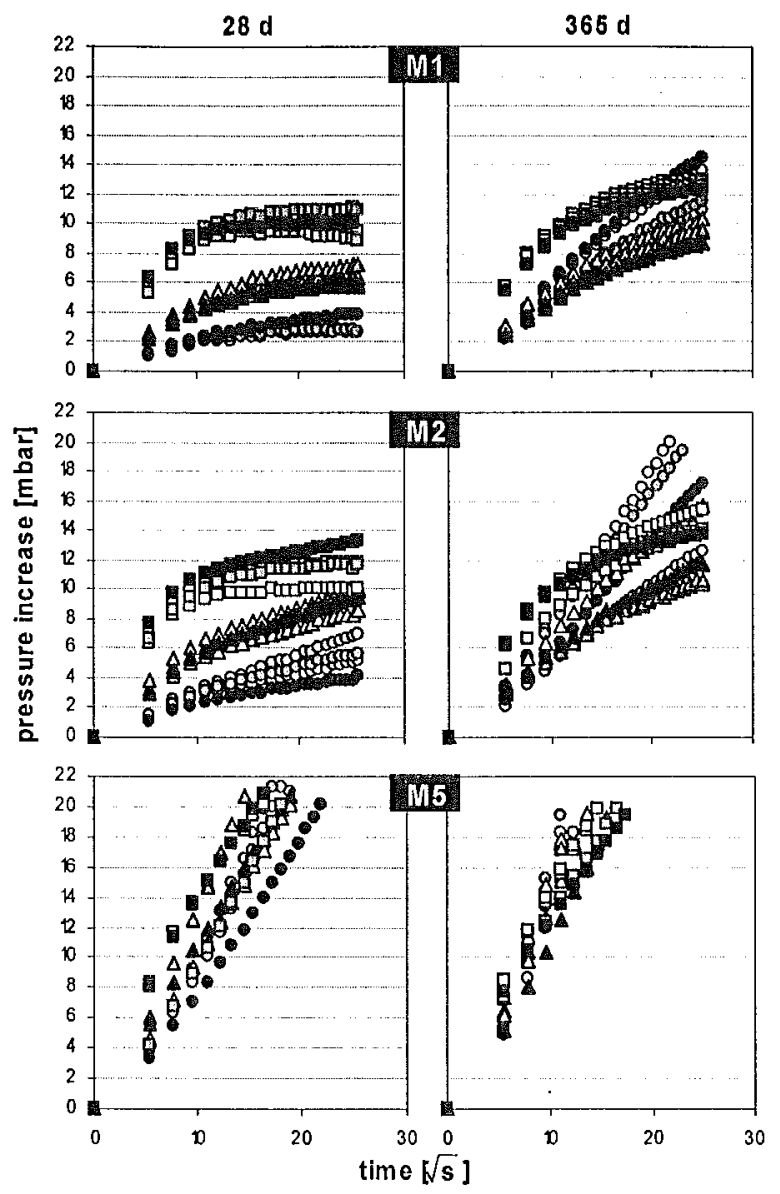

Fig. 3 - Pressure evolution in the measuring chamber in relation to the square root of time. Storage conditions: squares $=90 \% \mathrm{RH}$, triangles $=70 \% \mathrm{RH}$, circles $=35 \% \mathrm{RH}$. Time 0 corresponds to the setting of the stopcock. Due to the measuring procedure absolute pressures in the chamber are approximately 2 to $7 \mathrm{mbar}$ higher than the values shown in the diagram.

this study and almost independent from the duration of storage (age of sample). Only the concrete with $\mathrm{w} / \mathrm{c}$ ratio 0.62 (M5) does not exhibit this behaviour due to a very rapid pressure increase in all measurements. With increasing duration of storage at $90 \% \mathrm{RH}$ there is a small but systematic reduction of the curvature in the pressure evolution curves.

The pressure evolution curves for samples stored at intermediate $(70 \%) \mathrm{RH}$ show similar characteristics like those for high RH up to sample ages between two and three months, but the curvature is less pronounced and the linear part is steeper. For older samples stored at intermediate RH the pressure evolution is slower compared to samples stored at dry conditions and the $70 \%$ curves tend to decrease during the second half of the measuring period. Samples stored at low (35\%) RH show a systematic increase of the slope of the pressure evolution curves with age. Due to their almost linear shape the calculated permeability values $k T$ also increase with the duration of the storage period (Fig. 2).

\subsection{Correlation of $\mathrm{kT}$ with reference properties}

The permeability index kT of the covercrete as well as the compressive strength of separate concrete cubes are affected by the relative humidity during sample storage. The way $\mathrm{RH}$ is influencing these properties also depends on the quality of the concrete itself as shown for one year old samples in Fig. 4. Samples stored at $35 \% \mathrm{RH}$ always show the highest permeability values and the lowest strength. The lowest kTvalues for concrete mixtures MI-3 correspond to the storage condition of $70 \% \mathrm{RH}$ and at the same time to the intermediate compressive strengths. Going from dry to humid conditions concrete mixture M5 shows a steady increase of strength in parallel with a decrease in permeability.

The correlation of in-situ permeability $\mathrm{kT}$ with the values obtained by using the Cembureau method (oxygen permeability $\mathrm{kO}$ ) for one year old samples is shown in Fig. 5a. The kT measurements of the samples stored at 35\% and $70 \% \mathrm{RH}$ show a systematic underestimation compared to $\mathrm{kO}$. Except for M5 both permeability values decrease when moving from $35 \%$ to $70 \% \mathrm{RH}$. The $90 \% \mathrm{RH}$ storage condition is reducing the $\mathrm{kT}$ values for porous samples even more whereas for less permeable (low w/c ratio) concrete $\mathrm{kT}$ is increased significantly. The calculation of $\mathrm{kT}$ is assuming an open porosity of $15 \%$. Replacing this value by the determined capillary porosity values of the concrete mixtures leads to a consistent correlation (Fig. 5b) except for samples stored at $90 \% \mathrm{RH}$ conditions.

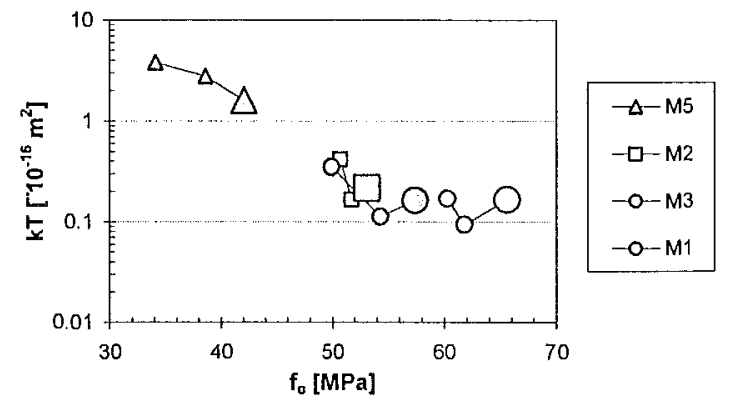

Fig. 4 - Correlation of compressive strength with covercrete permeability at the age of I year. Larger symbols represent samples stored at $90 \%$ RH (the symbols are connected in the order of the storage conditions: $90 \%-70 \%-35 \% \mathrm{RH})$.
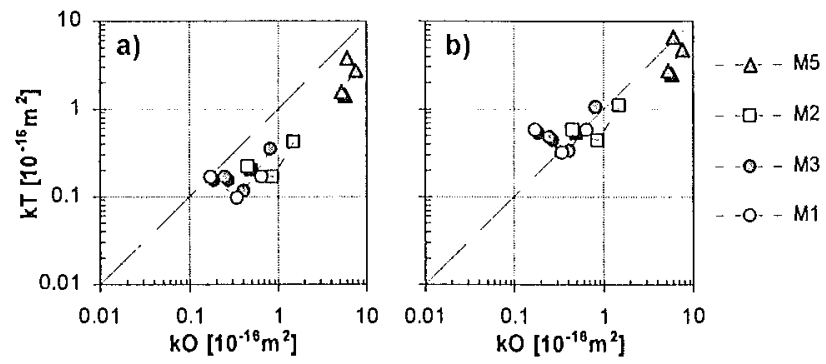

Fig. 5 - Correlation of covercrete permeability $\mathrm{kT}$ with oxygenpermeability kO of one year old samples: a) original values, b) values corrected for the porosity of the individual samples (symbols with shadow represent $90 \%$ RH condition, the symbols are connected in the order of the storage conditions: $90 \%-70 \%-35 \% \mathrm{RH}$ ). 

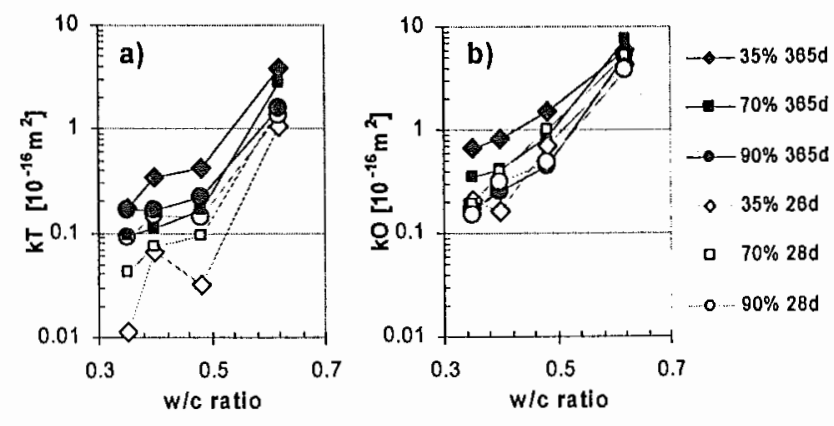

Fig. 6 - Permeability data from Torrent (left) and Cembureau method (right) for concrete samples 28 and 365 days old and stored at $35 \%, 70 \%$ and $90 \% \mathrm{RH}$ respectively.

The range of permeability data is larger for the Torrent method than for the Cembureau method (28 days and one year old samples, Fig. 6). With few exceptions both methods show a systematic and positive correlation with the w/c ratio. The impact of different storing conditions on the $\mathrm{kO}$ values (Cembureau method) at 28 days is small and not systematic whereas at the age of one year the permeability tends to be highest at dry $(35 \% \mathrm{RH})$ conditions and lowest at humid $(90 \%) \mathrm{RH}$. The change in $\mathrm{kO}$ from one month to one year is only significant for dry conditions leading to higher values. In contrast to $\mathrm{kO}$ the $\mathrm{kT}$ values for 28 day samples increase with higher $\mathrm{RH}$ and all $\mathrm{kT}$ values increase over time at fixed storage conditions. The change of $\mathrm{kT}$ is much bigger under $35 \% \mathrm{RH}$ than under higher humidity conditions leading to a complex situation at one year: the kT values for M1 to M3 (low w/c ratio) decrease form $35 \%$ to $70 \% \mathrm{RH}$ and then rise again in $90 \% \mathrm{RH}$ while for M5 with high $\mathrm{w} / \mathrm{c}$ ratio the $\mathrm{kT}$ values decrease from dry to humid conditions.

\section{DISCUSSION}

\subsection{Effects of storage condition}

In general high levels of RH lead to a better curing of concrete and cause a relative increase in strength. The same mechanism is also responsible for a certain densification of the porous microstructure leading to reduced connectivity of the porous network and affecting therefore the permeability of concrete. The oxygen permeability (Cembureau method on cored samples with defined preconditioning), the porosity properties and the strength are confirming the beneficial effects of curing and ongoing hydration while the air permeability values of the Torrent method show more complicated results. Before discussing these data some aspects of the measuring principals and the related theory shall be elucidated.

It is a common understanding that high levels of moisture content in concrete hinder the air or gas flow and lead to underestimation of the permeability properties [13]. Due to the fact that the Torrent permeability method was designed to be used on-site (without preconditioning) a method was introduced to correct the measured permeability and compensate for excessive moisture contents of the concrete tested. The basis for this correction was laid on the measurement of the electrical resistivity. Low values of permeability in combination with low electrical resistance may indicate an underestimation of the permeability due to a high degree of water saturation of the concrete. However, the results of this study show that the presence of moisture in concrete may lead to overestimations of the covercrete permeability.

\subsection{Torrent permeability method}

The pressure evolution curves in Fig. 3 show on the one hand the variability of independent measurements of parallel samples which may result from spatial variations in the distribution of aggregates. On the other hand major effects of the RH condition during storage on the curve shapes are evident.

For samples stored at dry $(35 \% \mathrm{RH})$ conditions the pressure is increasing quasi linear over the square root of time. This behaviour is interpreted to represent the situation without any interference with water or moisture and is in accordance with the theoretical equation (1).

A fast increase of the initial chamber pressure is observed by testing young concrete or samples stored under humid ( $90 \% \mathrm{RH})$ conditions. The rapid pressure increase is followed by a slowed down further increase which is almost linear to the square root of time. The change in the characteristic of the pressure increase curve is taking place at absolute pressures below approximately $20 \mathrm{mbar}$ (pressure increase of 6 to $14 \mathrm{mbar}$ in addition to the pressure in the inner cell before testing of 2 to $7 \mathrm{mbar}$ ). The value of $20 \mathrm{mbar}$ is close to the vapour pressure of water at $20^{\circ} \mathrm{C}(17.56 \mathrm{~mm} \mathrm{Hg} \approx 23$ mbar). It is concluded that the fast pressure increase at the early stage of certain measurements is related to the evaporation of water present in the sample and being exposed to low vacuum pressures. The slowed down and almost linear (in relation to square root of time) part of the pressure increase curve is supposed to be related to the effective air flow through concrete. In this second stage the air flow is very low and hardly related to the concrete quality ( $w / c$ ratio) indicating substantial hindrance by high levels of water saturation.

Samples stored at intermediate $(70 \%) \mathrm{RH}$ conditions show the largest variation of the pressure increase characteristics over the period of one year. Up to the age of 2 to 3 month the pressure increase curves show a contribution of evaporable water comparable to the samples stored at humid conditions but less pronounced. The quasi linear part of the second stage of the pressure increase curve shows almost the same or a slightly lower inclination than the curves of samples stored at dry conditions. So due to the effect of evaporable water the permeability $\mathrm{kT}$ is overestimated for all samples stored at humid conditions as well as for samples stored at $70 \% \mathrm{RH}$ for less than two to three months. The pressure increase curves for samples stored at $70 \% \mathrm{RH}$ for more than two to three months are always lower than those corresponding to dry conditions leading to the correct situation of higher permeability at lower humidity conditions due to better curing.

The trend towards higher permeability $\mathrm{kT}$ over time under dry conditions could result from progressive drying 
extending into the depth of the concrete and reducing successively the hindrance of the gas flow over time. On the other hand the progressive reduction of water saturation could also alter the pore structure (shrinkage) or even lead to microcracking. The $\mathrm{kO}$ values confirm the negative impact of dry conditions on the covercrete permeability. At the beginning of the Torrent measurements (young concrete stored under $35 \% \mathrm{RH}$ ) the $\mathrm{kT}$ values tend to decrease up to the age of one month before increasing again. This could be related to effects of evaporable water at early ages. Dense concretes (low w/c) seem to be less affected even though they show higher moisture contents.

The drying of the samples stored at $35 \%$ and $70 \% \mathrm{RH}$ is confirmed by the steady decrease of the moister content determined with the Tramex method. For the samples stored at $70 \% \mathrm{RH}$ the effects of evaporable water (pressure increase curve) correlate with Tramex readings of $5.5 \%$ or more. On the other hand for concrete samples stored for less than one month at dry $(35 \% \mathrm{RH})$ conditions (evaporable water effect still present) the moisture readings are above or close to $4 \%$. The results of the Tramex method are therefore not directly related to the state of water saturation which can cause problems due to evaporation effects. It has to be mentioned that the two methods affect distinct sample volumes non equal in with and depth.

For intermediate or high RH conditions we would expect the effective permeability of covercrete to decrease due to ongoing hydration and the development of a denser microstructure. But for samples stored at intermediate (70\%) RH the kT value slightly increases over time and even at $90 \% \mathrm{RH}$ a minor increase of the apparent permeability is recognisable. The conclusion based on these observations could be that the effect of drying is stronger than the effect of ongoing hydration. Nevertheless for one year old samples the Torrent method was able to confirm the positive effect of intermediate (and partly high) humidity conditions on the reduction of the concrete permeability.

Besides the difference in the measuring principle the test results for one year old samples under dry and intermediate conditions for the Torrent and the Cembureau method show a linear correlation, however the $\mathrm{kT}$ values show a systematic underestimation of the permeability. This can be explained by the fact that only a proportion of the total pore volume is contributing to the continuous pathway for gas transport and that the assumption of a relevant porosity of $15 \%$ is leading to a systematic underestimation of the permeability kT. Replacing this value in the calculation (1) by the measured volume of capillary pores (Table 2) leads to a very good agreement between the two methods.

Under identical environmental conditions the Torrent method differentiates the permeability of covercrete in the correct way. If the moisture content of concrete is not known only concrete with high penetrability may be characterised adequately with this method. In view of the inconsistent effects of moisture on the $k T$ value the application of this method under elevated $\mathrm{RH}$ conditions in the field needs careful evaluation and interpretation of the results. The presented results indicate that reliable values for the permeability kT without any further improvements of the method are achievable at dry conditions (35\% RH) after one month, at intermediate (70\%) $\mathrm{RH}$ after three to four months and at humid conditions $(90 \% \mathrm{RH})$ only for quite permeable concrete with $w / c$ ratios of 0.6 or higher. A drying period of hours or few days after wetting of a concrete surface seems to be very critical for the proper application of the Torrent method. A moisture reading of the Tramex method of more than $5.5 \%$ is related to high risks for evaporation effects and wrong $\mathrm{kT}$ values.

The shape of the pressure evolution curve itself could be used for the evaluation of the kT measurements. The presence of excess moisture close to the surface as well as further down in the concrete might be detected to a certain extent. To improve the Torrent method the vacuum applied on the concrete surface could be adjusted in a way to prevent from evaporation effects. Alternatively the software of the Torrent method could be altered to only analyse data above a certain minimum pressure. More research in the laboratory and in the field is necessary to clarify the possible improvements of the method.

Data of the author not shown in this publication indicates a major impact of temperature on the permeability kT. For concrete stored under dry condition at $20^{\circ} \mathrm{C}$ the reduction of $\mathrm{kT}$ is less than $20 \%$ if it is stored for one day and subsequently measured at $10^{\circ} \mathrm{C}$ or $5^{\circ} \mathrm{C}$. For concrete samples stored at $70 \%$ or $90 \% \mathrm{RH}$ for a period of one year and then tested at $10^{\circ} \mathrm{C}$ and $5^{\circ} \mathrm{C}$ the reduction of $\mathrm{kT}$ is more than $30 \%$. For low $w / c$ ratio concrete $\mathrm{kT}$ values may drop by more than $90 \%$. In view of the climatic conditions of real concrete structures the effect of temperature on the Torrent measurement needs to be clarified as well.

\section{CONCLUSIONS}

Under identical and controlled environmental conditions the Torrent method is able to differentiate the quality of concrete in the correct way. However, the absolute values of $\mathrm{kT}$ are affected by the age of the concrete and also by the moisture condition.

In addition to the reduction of the apparent gas permeability due to elevated water saturation of concrete the Torrent permeability kT also leads to overestimations of the intrinsic permeability. The latter effect is related to the application of a low vacuum leading to fast evaporation of water and consequently to increased gas volumes. The risk to overestimate the apparent permeability is high for young concrete and for concrete stored at $\mathrm{RH}$ of more than $70 \%$ for periods shorter than two month.

The Torrent permeability method offers big advantages in being completely non-destructive and easy to operate in the laboratory as well as in the field. Being quoted in the supplementary specification of the Swiss standard for concrete structures since 2003 and in view of the potential application of this method for quality control of concrete structures the adverse effects of moisture and temperature on the reliability of the results need to be further investigated. 
The analysis of the pressure evolution in the inner chamber during a measurement offers an interesting possibility to improve the reliability of the method. Alternatively the applied vacuum could be adjusted to reduce evaporation effects.

\section{ACKNOWLEDGEMENTS}

The author would like to thank the team of the Laboratory for Concrete and Construction Chemistry, namely M. Käppeli, K. Burkhard, K. Pfeiffer and W. Trindler. A. Leenann contributed significantly in designing the concrete mixtures and interpreting the results. Special thanks to R. Torrent for fruitful discussions.

\section{REFERENCES}

[1] Meyer, A., 'The importance of the surface layer for the durability of concrete structures', in 'SP-100: Concrete Durability, Katharine and Bryant Mather International Conference.-Vol. I', Atlanta, Georgia, USA, 1987 (American Concrete Institute) 49-61.

[2] Torrent, R.J, and Frenzer, G., 'A method for the rapid determination of the coefficient of permeability of the "covercrete"', in 'International Symposium Non-Destructive Testing in Civil Engineering (NDT-CE)', Berlin, Germany, 1995 (Deutsche Gesellschaft für Zerstörungsfreie Prüfung e.V.) $985-992$.

[3] Andrade, C., Gonzales-Gasca, C. and Torrent, R.J., 'Suitability of Torrent Permeability Tester to measure airpermeability of covercrete', in 'Durability of Concrete', Barcelona, Spain, 2000 (ACI international) 301-317.
[4] RILEM-TC116-PCD, 'Permeability of concrete as a criterion of its durability. Final report TC 116-PCD: Concrete durability - An approach towards performance testing', Mater, Struct. 32 (1999) 163-173.

[5] Paulmann, K. and Molin, C., 'On-site test methods', in 'RILEM Report 12: Performance Criteria for Concrete Durability', Eds. Kropp, J. and Hilsdorf, H.K. (E \& FN Spon, London, 1995) 258-279.

[6] Torrent, R.J. and Frenzer, G., 'Étude des méthodes de mesure et d'évaluation des caractéristiques du béton d'enrobage sur site' (VSS, 1995) 106.

[7] Torrent, R.J., 'A two-chamber vacuum cell for measuring the coefficient of permeability to air of the concrete cover on site', Mater. Siruct. 25 (1992) 358-365.

[8] SN-505-262/1, 'Concrete Structures - Supplementary Specifications' (sia, Zürich, 2003).

[9] Carcassès, M., Abbas, A., Ollivier, J.P. and Verdier, J., 'An optimised preconditioning procedure for gas permeability measurement', Mater. Struct. 35 (2002) 22-27.

[10] Dinku, A. and Reinhardt, H., 'Gas permeability coefficient of cover concrete as a performance control', Mater. Struct. 30 (1997) 387-393.

[11] www.tramexitd.com, 'Concrete Moisture Encounter', (Tramex Limited, 2003).

[12] RILEM TC 116-PCD, 'Recommendations of TC 116-PCD' Tests for gas permeability of concrete. A. Preconditioning of concrete test specimens for the measurement of gas permeability and capillary absorption of water, B. Measurement of the gas permeability of concrete by the RILEM - CEMBUREAU method, C. Determination of the capillary absorption of water of hardened concrete', Mater. Struct. 32 (1999) 174-179.

[13] Jacobs, F., 'Permeability to gas of partially saturated concrete', Magazine of Concrete Research 50 (2) (1998) 115-121. 